\title{
TRANSCRIAÇÕES POÉTICAS D'O SUMIÇO: TRADUÇÕES E RETRADUÇÕES LIPOGRAMÁTICAS DE POEMAS DE LA DISPARITION DE GEORGES PEREC - E OUTROS ${ }^{1}$
}

\author{
José Roberto Andrade FÉRES
}

\section{Introdução}

O lipograma é um texto escrito sem uma ou várias letras do alfabeto. Para a escrita de seu romance lipogramático intitulado La disparition — de agora em diante designado pela abreviação $L D$ - Georges Perec (1936-1982) privou-se do $e$, a letra mais frequente da língua francesa. Desde sua primeira publicação, em 1969, LD foi traduzido em onze línguas diferentes, mas jamais em português, idioma para o qual estamos nós a traduzi-lo (também sem o $e$, com o título $O$ sumiço — doravante: $O S$ ), há cerca de quatro anos, durante e após a conclusão de dois mestrados sobre a obra e algumas de suas traduções para outras línguas estrangeiras.

Assim, com o intuito de apresentarmos e justificarmos algumas das decisões tomadas em nossa tradução (ainda inacabada), escrevemos estas linhas.

No entanto, tanto o autor quanto os especialistas - dentre eles, os demais tradutores - de $L D$ pouco escreveram a respeito dos poemas lipogramatizados que se encontram no fim do décimo capítulo do romance, já uma espécie de tradução inserida no romance, "traduções lipogramáticas" 2 . E é por isso que tomamos tais versos como objeto deste estudo. Desta forma, não somente estaremos preenchendo uma lacuna na bibliografia produzida sobre o livro, mas também poderemos abrir a discussão (em português ${ }^{3}$ ) sobre aspectos gerais de nossa própria tradução, já que o que se apresenta nesses trechos em verso dos textos-fonte e alvo reflete, também, a forma na qual se constrói toda a trama — em prosa - do romance.

\footnotetext{
${ }^{1}$ Trabalho parcialmente apresentado no XI Congresso Internacional da ABRAPT e V Congresso Internacional de Tradutores, realizado em 23-26 de setembro de 2013, na UFSC, em Florianópolis.

${ }^{2}$ Georges Perec, pouco antes de escrever $L D$, tornou-se membro do OuLiPo (Ouvroir de Littérature Potentielle). $\mathrm{O}$ grupo pesquisava e propunha regras formais (contraintes) que trouxessem ou potencializassem a inspiração para a escrita de novos textos. O lipograma, uma das tais regras, pode gerar o que chamavam de "tradução lipogramática" (OuLiPo, 1988, p. 143), que consiste na tradução intralingual de um texto pré-existente, mas sem uma ou várias letras do alfabeto. Assim, as traduções lipogramáticas que Perec insere no fim do capítulo 10 de $L D$ são poemas célebres que ele reescreve sem o $e$.

${ }^{3}$ Publicamos em 2012 um primeiro artigo sobre os fundamentos de nossa tradução, artigo escrito em francês: "Traduire La disparition de Georges Perec vers le portugais: introduction aux choix théoriques et méthodologiques qui fondent $O$ sumiço". Tomamos aqui novos temas e retomamos alguns dos que já se encontravam ali, em língua portuguesa agora.
} 
Nada mais lógico, portanto, do que iniciarmos este artigo por uma visão global de $L D$ e, em seguida, abordarmos os poemas (fonte e alvo) a partir de desdobramentos dessa exposição introdutória ao romance de Georges Perec. Vários dos aspectos que veremos neste primeiro momento de introdução ao livro serão retomados na análise dos versos, enquanto outros, poucos, serão apresentados exclusivamente neste segundo instante. Assim, estando os poemas estreitamente relacionados com o restante do livro, pretendemos fornecer uma visão global também de nossa tradução, além de demonstrar que, embora tenhamos optado pela substituição de um certo número desses poemas - escolha que nos parece obrigatória, apoiando-nos sobretudo em algumas das escolhas de outros tradutores de $L D-$, o fizemos por razões que nos parecem legítimas e sem que essas substituições resultem em "perdas" para a nova rede textual que se tece em nosso texto-alvo.

Acreditamos que, tratando-se de um texto-fonte que se funda na potencialidade de especificidades da língua na qual foi escrito e na criatividade singular de um exímio manipulador das letras, não nos resta senão dar a nossa interpretação dessa manipulação, manipulando as letras dentro das possibilidades da nossa própria língua, bem como dentro da nossa própria capacidade. Se, por um lado, isso implica a impossibilidade de que, no final, exista "equivalência" (valores iguais) entre os textos-fonte e alvo, por outro, será possível constatar entre eles uma certa "correspondência", termo que empregamos — parcialmente inspirados em Antoine Berman ${ }^{4}$ — no seu sentido epistolar: nada impede que o tradutor, na sua lida com o autor - ambos sujeitos distintos $\mathrm{e}$ ambos sujeitos a diferentes circunstâncias - , consiga fazer com que o texto-alvo mantenha correspondência com o textofonte, faça com que eles troquem correspondências, troquem cartas entre si, dialoguem, se interroguem, se questionem, e respondam um ao outro, correspondam.

Em outras palavras, agora inspiradas nas de Lavoisier, o qual dizia que "na natureza, nada se cria, nada se perde, tudo se transforma", e transformando-as num amálgama com as

\footnotetext{
${ }^{4}$ Berman (1994, p. 94) explica o termo da seguinte maneira: “correspondência com o original e com sua língua. A palavra correspondência é voluntariamente escolhida aqui, por causa da sua rica polissemia e, também, da sua indeterminação. É um significante existencial e ontológico fundamental [...] E igualmente um significante concreto, como, em termos ferroviários, 'tomar' ou 'perder' a correspondência, em termos epistolares, 'manter correspondência' etc. A tradução sempre deve 'corresponder' com a pluralidade de todos esses significados" (nossa tradução de "correspondance à l'original et à sa langue. Le mot correspondance est ici volontairement choisi à cause de sa riche polysémie et, aussi, de son indétermination. C'est un signifiant existentiel et ontologique fondamental [...] Et également un signifiant concret : comme, en vocabulaire ferroviaire, 'prendre' ou 'manquer' la correspondance, en vocabulaire épistolier, 'entretenir la correspondance', etc. La traduction doit toujours 'correspondre' dans la pluralité de toutes ces significations").
} 
de Haroldo de Campos ${ }^{5}$, esperamos poder demonstrar que, na correspondência entre a nossa tradução e um texto criativo como $L D$ de Georges Perec, nada se cria, nada se perde, tudo se transcria.

\section{Visão global de La disparition}

A grosso modo, o que se conta em $L D$ é o misterioso desaparecimento, ou melhor, o sumiço — já que, em "desaparecimento", contamos com três aparecimentos do $e$ - de um dos personagens e, em seguida, a investigação feita pelos demais em busca do porquê desse sumiço. À medida em que suas investigações vão progredindo, vão todos, também, sumindo, a cada momento em que algum deles vislumbra a solução do mistério. Mas cada um desses sumiços — ou mortes, morridas ou matadas - esclarece um pouco mais o enigma. E assim vamos, como eles se vão, coletando as pistas deixadas pelos sumiços, até o fim do romance.

Claro, a trama, a história, o conto, contam muito, mas, quiçá, não tanto, ou, no máximo, tanto quanto conta a forma na qual tudo isso vai vir contado, vai tomar corpo, palavra por palavra, borrão por borrão, obscuro no branco, tinta na folha...

Entre as letras, entre as linhas, entre os livros (intertextos) que nos são apresentados por essa intriga policial, tudo nos remete ao metatextual ${ }^{6}$ : tudo nos conta como o que se conta é contado e, também, que o que se conta só é contado porque é assim contado; tudo são pistas que deixam transparecer a regra formal que se adota para a escrita do livro, o lipograma em $e$, o desaparecimento da letra $e$, e, ao mesmo tempo, que indicam que tudo o que se escreve ali tem por inspiração - e única razão de ser - esse mesmo sumiço. Para uma melhor compreensão do que tentamos dizer, vejamos por alto como é contada essa história que resumimos acima.

Antes de tudo, se passarmos os olhos no sumário do livro, veremos que somam-se 26 capítulos (em algarismos arábicos), organizados em VI partes (em algarismos romanos), mas existe um espaço em branco lá onde o capítulo 5 e a parte II deveriam estar. Ora, o $e$ é a quinta letra do alfabeto francês, no qual contam-se vinte e seis letras: por isso o sumiço do capítulo 5 dentre os 26 do total. Ora, o e é também a segunda das seis vogais francesas

\footnotetext{
5 Para Campos (1992, p. 35), "tradução de textos criativos será sempre recriação, ou criação paralela, autônoma porém recíproca". Mais tarde, já fazendo uso do termo "transcriar", dizia que "o tradutor tem que transcriar [...] transformar o original na tradução de sua tradução" (Campos, 1998, p. 82).

6 Adotamos aqui o conceito elaborado por Bernard Magné (1986, p. 77): "pertence ao metatextual todo enunciado que, em um texto, traz uma informação, denotativa e/ou conotativamente, sobre a scription [termo de Roland Barthes] do texto e/ou sobre sua escrita e/ou sua leitura" (nossa tradução de "appartient au métatextuel tout énoncé qui, dans un texte, apporte une information, dénotativement et/ou connotativement, sur la scription du texte et/ou sur son écriture et/ou sa lecture").
} 
(incluindo-se, portanto, o y): por isso o sumiço da parte II dentre as VI do total. Ora, é logo antes do capítulo 5 que lemos o bilhete deixado pelo personagem sumido que será o ponto de partida para toda a investigação dos demais, e ele se chama — nada mais, nada menos que Anton Voyl, cujo nome é tirado da palavra "vogal", em francês, voyelle: ou seja, excluindo-se a vogal sumida do texto, temos Voy[e]l[1e], Voyl. Ora, Anton Voyl tem cinco irmãos e, com certeza, não é por acaso que seus nomes formam o que é oulipianamente denominado uma "sequência vocálica" 7 : Anton Voyl, Douglas Haig Clifford, Hassan Ibn Abbou, Olga Mavrokhordatos, Ottavio Ottaviani - que constava primeiramente no cartório como Ulrich - e Yorich: A, [ai] (pronunciado como o $e$ no francês), I, O, U, Y. Ora, esses seis irmãos (como o número de vogais) são uma das gerações de uma família formada por vinte e seis membros (tal qual o número de letras do alfabeto). Ora, no topo dessa árvore genealógica — ou, digamos, abecedológica — , há um sujeito cuja descrição física apresentada no livro faz lembrar por demais a fisionomia do autor do livro, Georges Perec ( $L D$, p. 237-238), um tal de "Barbu" ("Barbudo"), assim apelidado por seu nome ser impronunciável ( $L D$, p. 246): Georges Pereec (?!), que praticamente só comporta a vogal $e$ no seu nome e que espalha por todos os cantos do livro ou suas consoantes - por exemplo, "G-P.R.C." ( $L D$, p. 77$)$ - ou duas palavras justapostas com uma ou as duas das iniciais em maiúsculo, por nenhuma razão aparente, a não ser por começarem com as iniciais do próprio nome do escritor, GP — para exemplificar, no fim do primeiro verso da quinta estrofe de "Booz assoupi", lemos (com grifos nossos) "grand Patron" ("grão Patrão" na nossa tradução - ver Anexos, p. 19) ${ }^{8}$. Ora, como se não bastasse, descobrimos no fim do livro - recomendo, então, que salte ao próximo parágrafo o nosso leitor, caso ainda não tenha lido o final do romance - que esse "Barbudo", além de ser o ponto originário de quase todos os personagens, era também aquele que colocava o ponto final nas suas vidas, que dava sumiço nos coitados logo que eles estavam próximos da solução do mistério, próximos da descoberta da vogal sumida, da revelação do nome do assassino: existe um paralelismo incontestável entre o "Barbudo" e o próprio escritor, este inserindo-se na ficção no papel daquele, ambos autores da vida e da morte dos demais.

No fim das contas, cada acontecimento, cada intertextualidade, cada nome próprio, cada frase de $L D$ nos reserva, ao menos, um duplo sentido: um superficial e outro metatextual; um no plano de uma diegese razoavelmente compreensível - embora, às vezes,

\footnotetext{
${ }^{7}$ Temos uma sequência vocálica quando as iniciais das palavras seguem a ordem das vogais da língua (OuLiPo, 1988, p. 263).

${ }^{8}$ Sobre as aparições das consoantes GP e Georges Perec inserindo-se como personagem em $L D$, ver Parayre, 1992, p. 212-223.
} 
bastante inverossímil - e outro que se refere à maneira pela qual foi gerado o livro. E isso talvez se complique ainda mais quando se trata da tradução dos poemas que abordaremos, que, como dizíamos, já são traduções, traduções lipogramáticas de versos de outros autores.

\section{Visão global d'O sumiço a partir da análise dos poemas do fim do capítulo 10}

A tradução poética sempre causa controvérsias, principalmente quando o tradutor está lidando com versos inseridos na prosa, como ao acaso, como se fossem uma espécie de artigo decorativo, fragmentos dispensáveis, palavras ao vento. E é mais ou menos dessa forma que os poemas do final do capítulo 10 são apresentados por um dos personagens de $L D$.

Para melhor nos situarmos na intriga, antes do sumiço de Anton (Antoin em nossa tradução), além de deixar um bilhete para os outros personagens, ele deixa vários manuscritos nos quais os últimos tentarão encontrar pistas que possam ajudá-los a desvendar o mistério desse sumiço. Dentre esses textos, existem seis poemas (como o número de vogais) que, segundo Olga, tendo sido escritos por poetas franceses famosos, e não pelo próprio Antoin, que, diz ela, só os teria transcrito, "palavra por palavra", eles não podem contribuir com esclarecimento algum, seriam, portanto, meramente decorativos. No entanto, como dissemos anteriormente, tratam-se de traduções lipogramáticas, e não de originais; são poemas célebres escritos por poetas franceses do fim do século XIX, mas - a única forma de figurarem em $L D$ - são reescritos por Perec, traduzidos lipogramaticamente sem o $e$. Assim sendo, cabe ao leitor constatar, por si só, que ele não está lendo os originais, mas uma tradução intralingual dos mesmos, sem a vogal sumida, que é exatamente a resposta para todo o enigma.

E o que fazemos nós, os tradutores, para traduzir aquilo que já é uma tradução (lipogramática), e que, ainda por cima, tenta se passar pelo texto original? Por exemplo, uma simples retradução para o português - sem o $e-$ desses seis poemas franceses lipogramatizados causaria tanto impacto em um leitor brasileiro, por mais habituado que fosse com poesia francesa? Sendo que a tradução (interlingual) já comporta tantas transformações, teria ele os instrumentos necessários para, como o leitor francês, descobrir que aquilo é um jogo, uma tradução (lipogramática) em vez de uma transcrição “palavra por palavra"?

Advém desse tipo de questionamento a solução adotada por uma grande parte das traduções de $L D$ até agora publicadas ${ }^{9}$, quase todas optando por: (I) uma retradução — para a

\footnotetext{
${ }^{9}$ Referimo-nos aqui a seis das onze traduções já publicadas de $L D$, dentre elas algumas que pudemos tocar com nossas próprias mãos e outras cujos autores (tradutores) tivemos a oportunidade de conhecer durante as Assises de la traduction littéraire en Arles de novembro de 2011 (<http://www.lr2l.fr/actualites/les-assises-de-latraduction-litteraire-arles-atlas-2011.html >), congresso internacional em que houve uma mesa-redonda composta por cinco tradutores de $L D$.
} 
língua-alvo, sem o $e$ - de "Vocalisations", que já consiste em uma tradução lipogramática de Perec a partir de "Voyelles" de Arthur Rimbaud, por ser este o mais explicitamente metatextual, além de ser o assunto da discussão que ocorrerá entre os personagens no capítulo que o segue; e, (II) quanto aos outros poemas, sempre na quantidade necessária para que a soma total corresponda ao número de vogais da língua-alvo, são traduções intralinguais e lipogramáticas - sem o $e-$ dos mais diversos - e famosos - poemas encontrados na tradição literária da própria língua-alvo, facilmente identificáveis pelo leitor dessas traduções. Constata-se também nessas traduções (III) a preocupação de se retomarem nos novos poemas os temas e aspectos recorrentes no romance.

No nosso caso, tentamos chegar a um meio-termo: inspiramo-nos na solução que parece ser a mais disseminada entre os tradutores de $L D$, mas mantivemos - retraduzindo-os para o português, sem o $e$ - outros dos poemas franceses, não somente o de Rimbaud, buscando seguir novas pistas que encontramos durante nosso estudo da obra, outras regras do jogo de Perec, expostas nos próximos parágrafos. Como adiantamento do resultado, leiamos o trecho (nos texto-fonte e alvo) que precede os poemas, o momento no qual Olga os introduz aos demais personagens, que, após alguns comentários, resolvem ler os versos:

Six madrigaux archi-connus, qu'on a tous lus dans un Michard ou dans un Pompidou, qu'on a tous appris quand on avait dix ans. Six madrigaux transcrits, mot à mot, sans aucun marginalia, par la main d'Anton:

- Bris marin, par Mallarmus

- Booz assoupi, d'Hugo Victor

- Trois Chansons du fils adoptif du Commandant Aupick.

- Vocalisations, d'Arthur Rimbaud.

Par-ci par-là, cinq ou six scazons font allusion aux dadas favoris d'Anton: l'obscur, l'immaculation, la disparition, la damnation. Mais nous savons qu'il s'agit là d'un pur hasard...

- Pourtant, affirma Amaury, nous n'avons pas grand choix: si Anton a cru bon d'accomplir la transcription, il nous faut y voir un jalon!

- Lisons donc, proposa Arthur Wilburg Savorgnan. D'abord, ils sont tout à fait jolis; puis qui sait si l'on n'y saisira pas un chaînon qu'Olga $n^{\prime}$ aurait point $v u$ ?

On lut donc (LD, p. 117).
Cinco madrigais mais um longo cântico: um trio tirado dum manual do Michard ou duma antologia do Pompidou, lidos por todos nós, francófonos; mais um outro trio, composto no idioma lusitano, um tanto curioso, pois o Antoin não dominava a língua. Mas foram todos transcritos, palavra por palavra, com o próprio punho, com marginália alguma:

- "Brisa marinha", do Mallarmus

— "Booz adormido", do Victor Hugo.

— "Transformado o amador na cousa amada", do Luís Vaz dos Camão

_ "A um rimador", do Olavo Bilac

— "Canção da cisão", do Vinicius

— "Vocalismos", do Arthur Rimbaud.

Aqui, ali, numas cinco ou mais linhas, há muita alusão às taras favoritas do Antoin: o obscuro, o imaculado, o sumiço, a danação. Mas tudo, claro, por obra do puro acaso...

— Mas, olha só — afirmou Amaury —, não sobra saída pra nós: como dá tanto trabalho uma transcrição assim, alguma pista o Antoin colocou aí!

- Por isso podíamos dar uma lida — propôs Arthur Wilburg Savorgnan - , não só pra gozarmos da formosura da compilação, mas, quiçá, pra captarmos algum grilhão não captado por Olga...

Assim, iniciaram a lida. 


\subsection{Seis (vogais) e vinte e seis (letras no alfabeto)}

Nota-se na citação acima que mantivemos a soma de seis poemas, o que significa que, na falta de uma melhor solução, consideramos o y como uma vogal corrente na língua-alvo. Embora este só apareça no português em empréstimos de palavras estrangeiras ou em nomes próprios, vimo-nos obrigados a lhe oferecer o estatuto de vogal, pois, como vimos no caso da estruturação do livro (em seis partes) ou na sequência vocálica formada pelos nomes de Antoin e seus cinco irmãos, ignorar o y acarretaria, por exemplo, a reorganização completa do romance e a eliminação de certos personagens. Ao menos no que concerne às vinte e seis letras do alfabeto e a todas as situações em que esse número desempenha o seu papel metatextual, o francês e o português se assemelham, já que tanto o $y$ quanto o $w$ foram adicionados no nosso abecedário no Acordo ortográfico da Língua Portuguesa de 1990.

Retornando aos versos, Perec reescreve e insere em seu romance cinco sonetos e um longo poema de Victor Hugo, na seguinte ordem:

a) "Brise marine", de Stéphane Mallarmé, que se transforma em "Bris Marin", de Mallarmus;

E) "Booz endormi”, de Victor Hugo, que se torna "Booz assoupi”, ainda de Victor Hugo;

i) "Recueillement", de Charles Baudelaire - bem como os dois que seguem logo abaixo -, que vira "Sois soumis, mon chagrin", do filho adotivo do comandante Aupick (referência biográfica ao impronunciável Baudelaire);

o) "Correpondances", que se metamorfoseia em "Accords";

u) "Les chats", que se traduz lipogramaticamente em "Nos chats";

y) e, por último, "Voyelles", de Arthur Rimbaud, que se lipogramatiza em "Vocalisations", outrossim de Arthur Rimbaud.

Se o nosso leitor fez-se atento aos marcadores - vocálicos - que colocamos na lista acima, já percebeu que não deve ser uma mera coincidência o fato de "Booz assoupi" — o longo poema de Victor Hugo, destacando-se do cenário sonetista que o envolve - ocupar a posição que ocuparia o $e$ na ordem das vogais. Resolvemos, portanto, dentre os poemas do texto-fonte, retraduzir para a língua-alvo tanto o de Rimbaud - presença indispensável igualmente aos olhos dos demais tradutores - quanto os de Victor Hugo e Mallarmé. Quanto aos três de Baudelaire, foram todos substituídos por traduções lipogramáticas de textos da tradição poética da língua portuguesa. Os motivos dessas escolhas serão expostos a seguir, começando pelas referências visuais à grafia do $e$.

\subsection{Referências visuais à grafia do $\mathrm{E}$}


Em meio às inúmeras pistas que apontam para a vogal sumida, encontram-se, por todo o livro, imagens que lembram a grafia do $e$, principalmente maiúsculo $(E)$. Por exemplo, antes de sumir, Antoin vê-se assombrado por várias imagens na hora em que olha fixamente para o tapete de sua casa, alucinações que sempre nos remetem à materialidade, ao traçado da letra $E$ ( $L D$, p. 19): "la Main à trois doigts" (“a Mão tridáctila"), que lembra a grafia do $E$ tanto por causa dos três dedos que a formam quanto por esse $M$ - maiúsculo - que, com uma rotação de $90^{\circ}$ no sentido anti-horário, muito se assemelha ao $E$; "sur son thorax noir trois articulations d'un blanc quasi lilial" ("tórax fuliginoso, no qual havia uma articulação trística dum branco próximo ao lirial"); ou "l'hautain portrait d'un roi brandissant un harpon" ("a figura altiva dum monarca brandindo um arpão”), que, juntamente com os últimos delírios, só pode nos fazer pensar em um rei específico, deus dos oceanos, Netuno, com o seu tridente, palavra substituída por arpão (geralmente usado debaixo d'água) por apresentar o $e$ também na língua francesa.

Como dizíamos na introdução deste trabalho, vários dos indícios dados na prosa serão reforçados nos poemas, tal qual esse arpão, que retorna no sexto verso de "Vocalisations" (Anexos, p. 23), tradução lipogramática do "Voyelles" de Rimbaud: "Harpons du fjord hautain, Rois Blancs, frissons d'anis", que, em nossa retradução, se transforma em "Monarca Branco, altivo arpão, frio frisson". Claro que, não podendo utilizar o plural de arpão (arpões) para os "Harpons" de Perec, poderíamos ter lançado mão das "lanças" que se encontram no original de Rimbaud ("Lances des glaciers fiers, rois blancs, frissons d'ombelles"), mas teríamos eliminado o indício metatextual que se cria com a rima interna entre tal verso lipogramatizado e o fragmento de prosa citado no parágrafo anterior. Ademais, é Mireille Ribière (1990, p. 57), insigne especialista em Perec e sua literatura "citacional", quem nos dá a pista: "Todo enunciado pré-formado, uma vez submetido a uma certa reescritura, pode ser levado a designar a contrainte [a regra formal, no caso, o lipograma]: qualquer desvio em relação ao original dá algum sinal" ${ }^{10}$. Para mencionarmos mais um caso de desvio que designa o sumiço do $E$, vamos passar rapidamente por "Booz".

Lemos no terceiro verso da sétima estrofe do "Booz endormi" (Anexos, p. 19) de Victor Hugo: "Les moissoneurs couchés faisaient des groupes sombres" (aproximadamente, “Os apanhadores deitados formavam grupos sombrios"). Já no "Booz assoupi” de Perec, também no terceiro verso da sétima estrofe, "Trois paysans blottis ont l'air d'un corps obscur" (aproximadamente, "Três camponeses amontoados parecem com um corpo obscuro"). Ora, o

\footnotetext{
${ }^{10}$ Nossa tradução de "Tout énoncé préformé, une fois soumis à certaine réécriture, peut être amené ainsi à désigner la contrainte : l'écart par rapport à l'original fait toujours signe".
} 
reescritor poderia ter optado por cinq, six, huit - cinco, seis, oito - camponeses amontoados para parecerem com um "corpo obscuro", mas ele escolhe três, como a "articulação trística" da alucinação de Antoin, os três traços paralelos que lembram "um corpo obscuro", a grafia (re)velada do $E$. E é por esse motivo que, mais uma vez, sempre em busca das pistas sugeridas pelas diferenças entre os originais e as reescrituras do autor de $L D$, optamos em nosso textoalvo pelo "Trois" (três) de Perec, e não pelo "Les" (os, plural do artigo masculino) de Victor Hugo, mesmo que esse três tenha de ser dito de outra maneira em "Booz adormido": "Mas, lado a lado, um trio influía um corpo obscuro".

Em suma, sendo o $E$ o 3 visto no espelho, a ausência da letra se faz omnipresente, graças à presença constante do número em $L D$. Já em nossa tradução, visto que o três é impronunciável, indizível, - digamos - inescritível, uma das saídas é empregarmos inúmeras palavras derivadas do número três (trio, tridáctilo, trístico, triplo, trífido), algumas delas já identificadas por nosso leitor nas citações anteriores, sem dúvida alguma. Outra das soluções, especificamente concernente aos poemas agora, foi substituir os três sonetos de Baudelaire, que, aos nossos olhos, mostrando-se menos significativos que os outros, possibilitam-nos reforçar a imagem refletida do $E: 3$ poemas de cada uma das culturas (fonte e alvo) é o resultado em nossa tradução.

\subsection{Transgressões ou erros voluntários}

Ainda sobre a onipresença da palavra "trois" (três, $3, E$ visto no espelho) em $L D$, Sara Greaves (2000, p. 110) afirma que "esse procedimento se insere em uma rede de procedimentos que permitem, apesar de tudo, que se inscreva a letra $e$ no texto". ${ }^{11}$ Um dos outros - vários - procedimentos que ajudam a tecer essa rede metatextual, de indícios que apontam para o $e$, é a transgressão das regras gramaticais e/ou ortográficas, erros voluntários e/ou neologismos que se inserem ao longo de todo o romance, seja na prosa, seja nos versos. Portanto, transgredimos as regras do português em $O S$, exatamente para não transgredirmos as regras de $L D$. No entanto, dado que estamos lidando com uma outra língua, com outras potencialidades, essas transgressões do texto-alvo quase nunca figurarão da mesma maneira ou no mesmo momento em que figuraram no texto-fonte, salvo raras exceções.

Começando por uma das exceções — no que concerne ao momento, mas não à maneira - dessas transgressões, encontramos no último verso de "Voyelles" (Anexos, p. 23), de Rimbaud, a cor "violet" (violeta). Em "Vocalisations", de $L D$, Perec escreve "violin",

\footnotetext{
${ }^{11}$ Nossa tradução de "ce procédé s'insère dans un réseau de procédés permettant d'inscrire malgré tout la lettre $e$ dans le texte".
} 
resultado da supressão da vogal $e$ de "violine", uma nuance do violeta. Para retraduzirmos, ou, melhor ainda, retranscriarmos no nosso "Vocalismos" esse erro, voluntariamente cometido pelo reescritor, escrevemos "violácio", em vez de "violáceo", a ortografia correta do adjetivo. Aproveitamos, assim, de um "erro" em potencial que abunda na língua-alvo: o fato de os brasileiros geralmente reproduzirem a pronúncia do $i$ lá onde o $e$ é átono, pronúncia tão corrente que se torna quase imperceptível, a ponto de supormos que muitos de nossos leitores sequer perceberão alguns desses erros voluntáreos ${ }^{12}$.

Passando agora para um exemplo de transgressão que foi deslocada no texto-alvo, encontramos, no segundo verso da vigésima estrofe do "Booz assoupi" (Anexos, p. 19) de Perec, no lugar do "troupeaux" (rebanhos) de Victor Hugo, "troupiau". Assim como manipulamos o "violáceo" — comentado acima —, Perec substituiu aqui o $e$ de "troupeau" por um $i$. Se tivéssemos a intenção — ou acreditássemos piamente na existência e/ou na eficiência - de uma equivalência, seríamos obrigados a traduzir tal "troupiau" por "ribanho" (rebanho) ou "ovilha" (ovelha). Mas preferimos ceder o lugar dessa pista a uma outra, a um sinônimo de cordeiro, "borro", uma palavra que vem reforçar uma nova rede metatextual que inserimos no texto-alvo com o intuito de transcriar uma outra rede - intraduzível, se, novamente, pensarmos em "equivalência" - do texto-fonte. Em resumo, não encontrando uma lexia que, sozinha, desse conta de um frequente "bourdon" de $L D$, cuja polissemia nos remete sempre ao seu significado no campo da tipografia - um elemento (tipo, palavra, ponto etc.) esquecido na hora da composição de um texto a ser impresso - empregamos em OS uma série de palavras que lembram "borracha" e "borrão", correspondendo - em rede, enquanto tecido composto por numerosos fios - com esse "bourdon": o fato de o $e$ sempre deixar sua marca, nas entrelinhas do texto, como se, na tentativa de apagá-lo com uma borracha, ainda ficasse um borrão, a tácita presença de sua ausência.

Mas, de volta ao voluntariamente incorreto "troupiau", se não cometemos erro algum naquele momento, o deslocamos — de certa maneira -, cometemos um outro, em compensação, lá onde não havia nenhuma incorreção em "Booz assoupi”: no penúltimo verso de "Booz adormido" (Anexos, p. 19), o "áurio" — cuja ortografia correta seria "áureo" traduz o corretíssimo “d'or” (de ouro) do último verso de Perec.

Por fim, em vista de um último exemplo de transgressão deslocada de uma posição do texto-fonte para uma outra do texto-alvo, podemos citar o quarto verso de "A um rimador"

\footnotetext{
${ }^{12}$ Só esperamos que os revisores de nossa tradução não venham a "corrigir" esses "erros", o que, infelizmente, ocorreu com o artigo de nossa autoria citado algumas páginas atrás: inseriram um $e$ em um dos exemplos que mencionamos e comentamos ali, dando a entender que, no fim das contas, usamos a tal vogal em OS...
} 
(Anexos, p. 21), que substitui o poema "Accords": "Trabalha, aí tima, aí lima, aí chora aí sua!”. Assim como não diremos quais são os poemas em língua portuguesa que deram origem às outras duas traduções lipogramáticas de $O S$ - reservando ao leitor o prazer da descoberta —, só diremos que o verso supracitado corresponde ao seguinte, de Olavo Bilac: “Trabalha, e teima, e lima, e chora e sua!". Portanto, eliminando o $e$ do verbo "teima", nossa versão aponta para uma pista metatextual marcada pelas tônicas dos verbos (em itálico abaixo), para uma sequência vocálica feita por Bilac, perfeita para ser refeita por nós, mas com defeito, faltando o $e$ (entre chaves aqui): “Trabalha, aí t[e]ima, aí lima, aí chora aí sua!”. Mesmo que o soneto “Accords", substituído por nós, não apresente nenhum erro ortográfico, os outros dois de Baudelaire - ou melhor, do filho adotivo do Aupick, já que não se podia escrever o nome do poeta (Charles Baudelaire) —, também substituídos em nossa tradução, ambos apresentavam palavras das quais foi tirado o $e$ : "guillotin" (guillotine) em "Sois soumis, mon chagrin" (Anexos, p. 20) e "sclavons" (esclavons) em "Nos chats" (Anexos, p. 22). Ficamos, portanto, com um crédito de erros voluntários, reutilizando-os em outros pontos do texto-alvo, como nessa nossa reescritura lipogramática de Bilac.

\subsection{Polissemia obscura do preto no branco}

A expressão "preto no branco", em português, existe tal e qual no francês, "noir sur blanc". Em $L D$, ela também toma um sentido metatextual, o da escrita, o da tinta (preta) na folha (branca). Trata-se, segundo Ribière (1990, p. 55), da "polissemia do branco, ao mesmo tempo cor e [espaço em] branco tipográfico, silepse à qual se anexam todas as metáforas metatextuais fundadas no cromatismo do branco e do preto". ${ }^{13} \mathrm{Em} L D$, uma dessas metáforas metatextuais - na qual, infelizmente, não poderemos nos aprofundar no momento, por termos um limite de folhas brancas a serem enegrecidas - é o "albatroz" (que carrega em si, no significante, tanto o alvor do branco quanto o negror do atro e de uma atrocidade), palavra que aparecerá, em todo o romance, somente seis vezes (tal qual o número de vogais). Por esse motivo, sobretudo, resolvemos manter o soneto "Bris marin" (Anexos, p. 18) em nossa tradução, por isto: no lugar dos "oiseaux" (pássaros) do segundo verso do "Brise marine" de Mallarmé, o Mallarmus de Perec escreve "albatros", também um "albatroz" na nossa "Brisa Marinha”, uma das suas seis - e únicas — aparições no livro. ${ }^{14}$

\footnotetext{
${ }^{13}$ Nossa tradução de "la polysémie du mot "blanc", à la fois couleur et blanc typographique, syllepse sur laquelle se greffent toutes les métaphores métatextuelles fondées sur le chromatisme du blanc et du noir".

${ }^{14}$ Gostaríamos de apontar para (e explicitar aqui nossa homenagem a) outra aparição (implícita esta) em nossa "Brisa Marinha": Augusto de Campos, de cuja tradução do poema de Mallarmé tomamos emprestada a bela rima entre "plagas" e "vapor a balouçar nas vagas".
} 
Nos poemas que abordamos aqui, contando somente neles, nos seis, há também duas palavras que só aparecem seis vezes: o branco (“blanc") e o preto (“noir”). Quanto ao branco, problema algum: basta contar nos dedos e o leitor só o encontrará seis vezes (como o número de vogais) nos nossos poemas, mesmo que três dos nossos sonetos não sejam os mesmos de $L D$ - por exemplo, lá no segundo verso da "Canção da cisão" (Anexos, p. 22), que não constava em $L D$, Vinicius nos brinda com um "Branco" desses. No caso do preto, a coisa já fica mais obscura: visto que o preto não se pode escrever em $O S,{ }^{15}$ a outra palavra que virá na soma de seis nos nossos poemas é o "obscuro" (ou "obscura"), como, igualmente, na "Canção da cisão". Nada se cria, nada se perde: trocando seis noir por meia dúzia de "obscuro", tudo se transcria - até mesmo uma autobiografia, nosso próximo tema.

\subsection{Autobiografia do autor: encriptação}

Georges Perec (1975, p. 41) escreve em $W$ ou le souvenir d'enfance que o projeto de escrever a sua história de vida surgiu ao mesmo tempo que seu projeto de escrita. Mais tarde, ele se explicará melhor: "todos meus livros, somados, poderão funcionar como uma autobiografia também. Só que a autobiografia não é somente contar os acontecimentos que se deram na vida de alguém". ${ }^{16}$ E encaixa-se aqui uma certa autobiografia "encriptada", ou cifrada, escrita em cifras, ou em códigos - quase - secretos. Por exemplo, Bernard Magné (2005, p. 57), um dos especialistas que mais se embrenharam nesses segredos, nas marcas autobiográficas perecquianas, nos aponta para várias aparições do número 43 na obra de Perec, lembrança do ano em que sua mãe foi deportada, sumindo para nunca mais voltar. Daí, aliás, vem nossa decisão de, apesar de substituirmos três dos poemas de $L D$ aqui tratados, continuarmos com "Booz" - que logo comentaremos - e com sonetos somente, feito Perec, pois sonetos são formados de quartetos e tercetos, estrofes de 4 e 3 versos: 43.

De volta a Magné (2005, p. 24), ainda sobre esses "biografemas" (termo que empresta de Roland Barthes) da encriptação perecquiana:

Não é um caso de curiosidade biográfica. Ao se trazerem à luz esses biografemas, o que importa é que, uma vez descobertos, eles revelam um intenso trabalho de escritura [...].

\footnotetext{
${ }^{15}$ Os espanhóis passaram por um problema semelhante na feitura de El secuestro, porém oposto: eliminando o $a$ da tradução, podiam escrever negro, mas blanco, não.

${ }^{16}$ Nossa tradução de "la somme de mes livres pourra fonctionner aussi comme une autobiographie. Seulement, l'autobiographie, ce n'est pas seulement raconter les événements qui sont arrivés dans la vie de quelqu'un" (Perec, 2003, p. 64).
} 
Portanto a encriptação não se reduz a uma simples transferência [...]. O que o scriptor retém dela não é a dimensão do referente, mas a da linguagem. ${ }^{17}$

É sob a luz desse comentário de Magné que falávamos da ficcionalização do nome de Georges Perec — com tanto $e$ — na intriga de $L D$ e que, mais adiante, afirmávamos que não é à toa que há um poema diferente dos demais em meio aos seis poemas do final do capítulo 10 , ocupando a posição que o $e$ ocuparia se os considerássemos ordenados de acordo com uma sequência de vogais: é em "Booz assoupi” que se esconde a assinatura, a marca autobiográfica maior de $L D$, o nome impronunciável desse "Barbudo" que é - como comenta Claude Burgelin (2002, p. 107) - "auteur" e "ôteur" de vidas ao mesmo tempo, o autor da vida e da morte desses personagens de letras e papel.

No entanto, para que se descubra esse "biografema", o qual revela "um intenso trabalho de escritura", é igualmente necessário um intenso trabalho de leitura. Assim, para a nossa leitura - e, consequentemente, para nossa tradução — , seguimos uma pista dada por um personagem de um romance de Perec (2001, p. 93) publicado postumamente, 53 Jours: “a verdade que busco não está no livro, mas entre os livros [...] é preciso ler entre os livros como se lê nas "entrelinhas", 18 .

Em $W$, um dos poucos livros onde a autobiografia é abordada abertamente pelo escritor, ele nos conta de onde vem seu sobrenome: "O sobrenome da minha família é Peretz. Ele se encontra na Bíblia. Em hebraico, quer dizer 'buraco"”19.

Ora, primeiramente, podemos ler nos tantos "trous" de $L D$ ("buracos" de $O S$ ) uma pista que, se já sugeria o metatextual por o $e$ deixar certos buracos no texto, ainda se relaciona com o nome (impronunciável) do autor, o qual só pode figurar no romance por sob máscaras.

Em um segundo momento, devemos sublinhar que "Booz assoupi" é o único, dentre os seis poemas do fim do décimo capítulo, que é narrativo, que conta uma história, e uma história cujo tema, assim como $L D$, envolve uma misteriosa trama familiar. Mas essa narração em versos é uma reescritura do "Booz endormi” de Victor Hugo, o qual, por sua parte, já era uma reescritura da história bíblica contida no Antigo Testamento, no Livro de Rute, o qual se

\footnotetext{
${ }^{17}$ Nossa tradução de "Ce n'est pas affaire de curiosité biographique. S'il importe de mettre au jour ces biographèmes, c'est qu'une fois découverts, ils révèlent un intense travail d'écriture. [...] L'encryptage ne se réduit donc pas à un simple transfert. [...] Ce que le scripteur en retient, ce n'est pas la dimension référentielle mais langagière".

${ }^{18}$ Nossa tradução de "la vérité que je cherche n'est pas dans le livre, mais entre les livres [...] il faut lire entre les livres comme on lit "entre les lignes"'.

${ }^{19}$ Nossa tradução de "Le nom de ma famille est Peretz. Il se trouve dans la Bible. En hébreu, cela veut dire "trou" " (Perec, 1975, p. 51).
} 
encerra com a genealogia de Davi, esta começando, exatamente, por "Pereç" — uma das variações da ortografia de "Peretz", do qual vem Perec, como vimos logo acima:

Voici la postérité de Pérèç :

Pérèç engendra Heçrôn [...]. Et Obed engendra Jessé et Jessé engendra David. ${ }^{20}$

Enfim, a partir desse intenso trabalho de leitura - entre os livros —, chegamos ao nome impronunciável do "Barbudo", ao biografema encriptado e metatextual que é a própria assinatura de Perec, logo ali, no "Booz assoupi", o segundo dos seis poemas aqui abordados, ocupando a vaga do $e$ entre as seis vogais. Concluímos, assim, que — relembrando Magné —, não se trata de uma "curiosidade biográfica", o que o "scriptor retém" dessa marca autobiográfica é a dimensão da linguagem, a materialidade do seu nome, as suas letras. Como diria um dos membros da equipe tradutora de $L D$ para o espanhol, Marc Parayre (1992, p. 520), "as palavras, querendo ou não, antes de serem portadoras de mensagens, são portadoras de letras"21. Portanto, para darmos à luz $O$ sumiço, não podíamos dar sumiço no "Booz", nesse intertexto metatextual que assina a obra, que faz com que o autobiográfico se torne metatextual e vice-versa, - conquanto ainda haja um porém: colocamos a citação acima em francês, porque Peretz ou Pereç ou Perec, nas bíblias em língua portuguesa que pesquisamos, é, em algumas, Perez ou Pérez, em outras, Farez ou Farés... De que valeria, então, uma pista como essa, se um dos leitores da nossa tradução fosse procurar Peretz ou Pereç ou Perec na sua Bíblia, e só encontrasse Perez ou Pérez ou Farez ou Farés?

\subsection{Autobiografia do tradutor: encriptada na autobiografia do autor}

Rimbaud diria: "Eu é um outro". Diríamos nós: "Eu somos um outro”. Eu somos este majestático "nós" de modéstia acadêmica que, neste instante, por livre e espontânea pressão, não tem outra opção senão apropriar-se e ampliar as palavras de Perec — citadas uns cinco parágrafos atrás:

O sobrenome da minha família é Féres. Ele se encontra na Bíblia, ora como Perez ou Pérez ora como Farez ou Farés, como meus antepassados se chamavam antes de migrarem do Líbano para o Brasil. Em hebraico, quer dizer "buraco".

Assim, mais uma vez, nesse buraco claro-obscuro, nada se cria, nada se perde: seja Peretz ou Pereç transformando-se em Perec (o sobrenome do autor), seja Perez ou Pérez ou

\footnotetext{
${ }^{20}$ La Bible de Jérusalem. Editions du Cerf, 1998, p. 371.

${ }^{21}$ Nossa tradução de "Les mots, qu'on le veuille ou non, sont porteurs de lettres avant que de messages".
} 
Farez ou Farés transformando-se em Féres (o sobrenome do tradutor, o meu sobrenome), "Booz" não perde o seu valor metatextual e autobiográfico.

\section{Conclusão}

Cremos que, de uma forma ou de outra, unindo-se os fios que tecemos acima, nosso leitor deverá constatar, junto a este "nós" — que é vário e engloba mais que o autor e o tradutor, inserindo-se aqui, além de tudo, tantas intertextualidades —, que conseguimos atar inúmeros nós entre os textos-fonte e alvo e entre a prosa e a poesia de ambos.

Embora três dos poemas do texto-fonte tenham sumido, outros três surgiram no textoalvo, tentando cumprir funções que não são as mesmas, mas que trocam correspondências entre si, que apresentam respostas diferentes a questionamentos semelhantes. Malgrado o possível deslocamento de algumas pistas, deslocamento espacial, temporal ou funcional, propõe-se sempre no texto-alvo uma resposta ao texto-fonte, respostas inspiradas nas respostas que o próprio texto-fonte parece nos propor - e outras que uma tradição de traduções de La disparition nos vem propondo. Ainda que o autor pareça desaparecer hora ou outra, o tradutor sempre tenta colocar a sua máscara e se passar pelo autor: assim como Perec o fez na pele - de letras - do "Barbudo", o tentamos fazer na pele — de letras — de ambos.

Obviamente, em resposta a tantas questões e concessões, a quantidade destas folhas não nos permite senão uma pequena quantia de esclarecimentos. Porém, existe um que não podemos deixar passar em branco: nossa tradução, ainda inacabada, poderá vir a passar por inúmeras modificações. Nenhuma de nossas decisões é final, e, talvez, nem mesmo o prelo ou a impressão as tornem definitivas.

La disparition é uma fonte inesgotável de adivinhações, de jogos de linguagem, de charadas metatextuais, e $O$ sumiço nada mais será que um dentre os - igualmente inesgotáveis jogos tradutórios possíveis, um tabuleiro nosso, onde tentamos espalhar peças com que o nosso leitor possa brincar, mais ou menos, dentro das regras do jogo estabelecido entre Georges Perec e os leitores do seu próprio texto. As peças são outras, e o jogo é quase outro: a língua é outra, a cultura, as circunstâncias, o sujeito que escreve a tradução — ainda brincando com Rimbaud — somos outros. Segundo Haroldo de Campos (1992, p. 43):

A tradução de poesia (ou prosa que a ela equivalha em problematicidade) é antes de tudo uma vivência interior do mundo e da técnica do traduzido. Como que se desmonta e se remonta a máquina da criação, aquela fragílima beleza aparentemente intangível que nos oferece o produto acabado numa língua estranha. E que, no entanto, se revela suscetível de uma vivissecção implacável, que lhe revolve as entranhas, para trazê-la novamente à luz num corpo linguístico diverso. 
A partir da nossa "vivência interior", individual e múltipla ao mesmo tempo, perpassada tanto pelos estudos que fizemos sobre a "máquina da criação" da obra quanto pelas nossas próprias experiências no campo da escrita, é a partir dessa mistura que irá surgir O sumiço. É no contato, no diálogo, na correspondência entre os textos-fonte e alvo e todos esses textos e contextos que os permeiam e os transcriam, que trazemos à luz nossa transcriação de La disparition, certa e assumidamente revolvendo-lhe "as entranhas". Nossas peças são diversas das de Perec, "num corpo linguístico diverso", através de um corpo de carne e osso que é igualmente diverso, mas peças diversas que também tentam se reunir numa nova "máquina da criação", que também funcione.

Assumimos as diferenças entre La disparition e $O$ sumiço, pois não buscamos nem acreditamos na existência de uma "equivalência" entre textos criativos e traduções que pretendam fazer uso da criatividade - como nós o pretendemos, pois nos vemos obrigados a tal. Mas buscamos e acreditamos, sim, na existência de um diálogo entre os textos e contextos, fontes e alvos, todos discorrendo em torno de um mesmo assunto, de um mesmo gesto - aqui, o da escrita pautada por contraintes, por regras formais.

Sendo essa própria escrita — formalmente regrada - o verdadeiro protagonista de $L D$ - um $e$ ausente que se faz presente em cada canto do texto, em cada marca metatextual (e autobiográfica, como vimos, sempre relacionada com o nome do autor) —, é em prol dessa escrita metatextual que pretendemos trabalhar, da melhor forma que a possamos transcriar, mas sempre conscientes de que a nossa talvez não seja a melhor forma possível — se é que é possível que exista, de alguma forma, a melhor forma possível.

\section{Referências bibliográficas:}

BERMAN, Antoine. Pour une critique des traductions: John Donne. Paris: Gallimard, 1994.

BURGELIN, Claude. Georges Perec. Paris: Seuil, 2002. p. 107.

CAMPOS, Haroldo de. Metalinguagem \& outras metas. $4^{\text {a }}$ ed. São Paulo: Perspectiva, 1992.

. Pedra e luz na poesia de Dante. Rio de Janeiro: Imago, 1998.

GREAVES, Sara. De La disparition de Georges Perec à Vanish'd! de John Lee: la traduction traduite. Palimpsestes 9, p. 105-115, 1995. 
FÉRES, José Roberto Andrade. Traduire La disparition de Georges Perec vers le portugais: introduction aux choix théoriques et méthodologiques qui fondent $O$ sumiço.

Traduzires, v. 1, n. 2, p. 48-61, 2012.

MAGNÉ, Bernard. Métatextuel et lisibilité. Protée, v. 14, n. 1-2, 1986.

Georges Perec. Paris: Armand Colin, 2005.

OULIPO. Atlas de littérature potentielle. Paris: Gallimard, 1988.

PARAYRE, Marc. Lire La disparition de Georges Perec. Toulouse, 1992. Tese (Doutorado em Lettres Modernes) — Université de Toulouse le Mirail.

PEREC, Georges. La disparition. Paris: Denoël, 1969.

. W ou le souvenir d'enfance. Paris: Denoël, 1975.

53 Jours. Collection Folio, n. 2547. Paris: Gallimard, 2001.

Entretiens et conférences, Volume II. BERTELI, Dominique; RIBIÈRE,

Mireille (Eds.) Nantes: Joseph K, 2003.

RIBIÈRE, Mireille. "Maudit Bic!” ou la maldiction. Études littéraires, v. 23, n. 1-2, 53-78, 1990. 


\section{Anexos: poemas sumidos, surgidos e ressurgidos}

Brise marine (Stéphane Mallarmé)

La chair est triste, hélas ! et j'ai lu tous les livres. Fuir ! là-bas fuir ! Je sens que des oiseaux sont ivres D'être parmi l'écume inconnue et les cieux ! Rien, ni les vieux jardins reflétés par les yeux Ne retiendra ce cœur qui dans la mer se trempe O nuits ! ni la clarté déserte de ma lampe Sur le vide papier que la blancheur défend Et ni la jeune femme allaitant son enfant. Je partirai ! Steamer balançant ta mâture, Lève l'ancre pour une exotique nature! Un Ennui, désolé par les cruels espoirs, Croit encore à l'adieu suprême des mouchoirs ! Et, peut-être, les mâts, invitant les orages Sont-ils de ceux qu'un vent penche sur les naufrages Perdus, sans mâts, sans mâts, ni fertiles îlots...

Mais, ô mon cœur, entends le chant des matelots !
Bris marin (Mallarmus) (La Disparition, 118)

Las, la chair s'attristait. J'avais lu tous folios. Fuir! Là-bas fuir! J'ai vu titubant l'albatros D'avoir couru aux flots inconnus, à l'azur ! Nul, ni nos noirs jardins dans ton voir aussi pur N'assouvira mon flanc qui, marin, s'y baignait. O, Nuits ! Ni l'abat-jour insolant qui brûlait Sur un vain papyrus aboli par son Blanc Ni la bru qui donnait du lait à son Infant. Partirai! O transat balançant ton grand foc, Sors du port ! Cinglons sur l'inouï lointain du roc. Un chagrin abattu par nos souhaits d'un soir Croit toujours au salut qui finit au mouchoir. Mais parfois un dur mât invitant l'Ouragan Fait-il qu'un Aquilon l'ait mis sur un brisant Omis, sans mâts, sans mâts, ni productifs îlots. Mais ouïs nos marins chantant aux apparaux !
Brisa marinha (Mallarmus) (O Sumiço)

Fica o corpo atristado. Li todos os livros. Fugir! Fugir ao largo! O albatroz, ao ar lívido, Vi zanzar zonzo, hora ou outra a um fluxo obscuro! Nada, tampouco os atros jardins no olhar puro Minha alma afastarão das águas do alto-mar. Tampouco, ó Madrugada, a lâmpada a aclarar O vão fólio abolido por um próprio Branco, Tampouco a mama moça a dar mamá ao Infanto. Parto daqui! Vapor a balouçar nas vagas, Iça âncora! Singra às inauditas plagas. O amuo, magoado por um fado infando, Aspira à saudação das mãos 'inda abanando. Mas tais mastros, quiçá, clamarão por Tornado, Sob cujo Aquilão sobra, ao barco naufragado, Ilha alguma a avistar, mastro algum, mastro omisso. Mas marujos ouvi: cantam no passadiço! 
Booz endormi (Victor Hugo)

Sa barbe était d'argent comme un ruisseau d'avril. $[\ldots]$ Laissez tomber exprès des épis, disait-il.

$[\ldots]$

Booz était bon maître et fidèle parent ;

$[\ldots]$

Donc, Booz dans la nuit dormait parmi les siens ; Près des meules, qu'on eût prises pour des décombres. Les moissonneurs couchés faisaient des groupes [so

Et ceci se passait dans des temps très anciens. [...

10 Et ce songe était tel, que Booz vit un chêne Qui, sorti de son ventre, allait jusqu'au ciel bleu ;

Une race y montait comme une longue chaîne ;

Un roi chantait en bas, en haut mourait un dieu.

$[\ldots]$

L'ombre était nuptiale, auguste et solennelle ;

$[\ldots]$

Les collines ayant les lys sur leur sommet.

$[\ldots]$

Les grelots des troupeaux palpitaient vaguement ;

$[\ldots]$

Quel dieu, quel moissonneur de l'éternel été

Avait, en s'en allant, négligemment jeté

Cette faucille d'or dans le champ des étoiles.
Booz assoupi (Victor Hugo) (La Disparition, 119) Booz adormido (Victor Hugo) (O Sumiço)

Son poil avait du Blanc ainsi qu'un ru d'avril.

$[\ldots]$

Laissons-lui à propos choir du grain, disait-il.

[...]

Si Booz, bon cousin, si Booz, grand Patron,

[...]

Donc, Booz dans la nuit dormait parmi son grain

Non loin du haut mulon qui paraissait un mur.

Trois paysans blottis ont l'air d'un corps obscur; mbres Or tout ça arrivait dans un antan lointain.

[...]

Ainsi fut la Vision: Booz vit un grand tronc

Qui, sorti du nombril, allait jusqu'à l'azur;

Un sang vrai y montait ainsi qu'un long chaînon;

Un roi chantait au bas; là-haut mourait un pur.

[...]

L'obscur planait nuptial, infini, imposant.

[...]

Il y avait un lys au flanc du vallon Blanc.

[...]

$\mathrm{Au}$ loin, un sourd troupiau va tintinnabulant.

[...]

Qu'un divin paysan du toujours automnal

Avait, partant au loin, dans un mol abandon,

Conduit son chariot d'or sur son sillon astral.
Booz adormido (Victor Hugo) (O Sumiço)

Na barba, o Branco, o brilho do rio luzia.

[...]

"Larga, como ao acaso, mais dos grãos", dizia.

[...]

Booz tinha a postura do bom, grão Patrão;

[...]

Assim, Booz dormia com todos do apanho,

Logo ao lado do trigo, às pilhas, como muros;

Mas,lado a lado,um trio influía um corpo obscuro;

Ora, aquilo ocorria nas datas do antanho.

[...]

Booz via um carvalho a brotar na Visão,

Subindo, indo do umbigo rumo ao vasto páramo;

Vinha ali uma raça alçar longo grilhão:

Canta um monarca abaixo; acima, um puro,

[- matam-no.

[...]

O obscuro, nupcial, vogava augusto no ar;

[...]

Havia um lírio ali, no topo do val Branco.

[...]

Voga o rumor surdo dos borros com os guizos;

[...]

Qual foiçador divino do outono infinito

Largara o áurio foicinho só, solto, caído,

Indo sulcar à larga outros campos lunários? 
Trois chansons (La Disparition, 122)

(par un fils adoptif du Commandant Aupick)

Sois soumis, mon chagrin

Sois soumis, mon chagrin, puis dans ton coin sois sourd

Tu la voulais la nuit, la voilà, la voici

Un air tout obscurci a chu sur nos faubourgs

Ici portant la paix, là-bas donnant souci.

Tandis qu'un vil magma d'humains, oh, trop banals, Sous l'aiguillon Plaisir, guillotin sans amour,

Va puisant son poison aux puants carnavals,

Mon chagrin, saisis-moi la main; là, pour toujours

Loin d'ici. Vois s'offrir sur un balcon d'oubli,

Aux habits pourrissants, nos ans qui sont partis;

Surgir du fond marin un guignon souriant;

Apollon moribond s'assoupir sous un arc

Puis ainsi qu'un drap noir trainant au clair ponant

Ouïs, Amour, ouïs la Nuit qui sourd du parc.

\section{(O Sumiço)}

Transformado o amador na cousa amada (Luís Vaz dos Camão)

Transformado o amador na cousa amada, por motivo do muito imaginar,

não aspira a algo mais compartilhar, pois consigo há a partilha transcriada.

Dada a cousa já na alma transformada, nada mais sobra ao corpo a apropriar? Por si só, no amor próprio traz um lar, pois consigo tal alma traz liada.

Mas tão linda, tão pura arrazoação, co'a qual são conformados alguns tipos, assi $[\mathrm{m}]$ como à minha alma dita a Norma,

tão só voga no plano da Razão:

[o] vivo ou puro amor por qual sou tido, como toda substância, busca a forma. 
Accords (La Disparition, 123)

(par un fils adoptif du commandant Aupick)

Sois, Cosmos, un palais où un vivant support A parfois fait sortir un propos tout abscons

Un passant y croisait la Symbolisation

Qui voyait dans un bois un son au fond du cor.

Ainsi qu'un long tambour qui au loin s'y confond Dans un profond magma obscurci mais global,

Massif où la nuit voit l'attrait d'un abyssal

Jouxtant irisations, parfums coruscants, sons.

Il y a un parfum mimant la chair du faon,

Doux ainsi qu'un hautbois, clair ainsi qu'un gazon

Puis l'air d'un corrompu, d'un pourri triomphant

Ayant l'impulsion d'un tissu d'infini

Ainsi qu'un romarin, un iris, un jasmin

Qui chantait nos transports dans l'Amour ou l'Instinct.
A um rimador (Olavo Bilac)

(O Sumiço)

Distado do vão turbilhão da rua,

Monástico, lavra a obra! Na harmonia

Do claustro, na pacata calmaria,

Trabalha, aí tima, aí lima, aí chora aí sua!

Mas possa a forma ocultar a porfia

Do obrar; construa a viva trama sua

Dum modo tal, qual figurando nua,

Rica mas sóbria, moldada à Ilíada.

Não surja na fábrica a provação

Do obrador. Natural, apraza à vista,

A obumbrar os andaimos da mansão.

Pois a formosura, irmã da Justiça,

Obra pura, inimiga à apuração,

Mana da força da Graça simplíssima. 
Nos chats (La Disparition, 124)

(par un fils adoptif du commandant Aupick)

Amants brûlants d'amour, savants aux pouls glaciaux,

Nous aimons tout autant dans nos saisons du jour

Nos chats puissants, mais doux, honorant nos tripots

Qui sans nous ont trop froid, nonobstant nos amours.

Amis du Gai Savoir, amis du doux plaisir,

Un chat va sans un bruit dans un coin tout obscur.

O, Styx, tu l'aurais pris pour ton poulain futur

Si tu avais, Pluton, aux sclavons pu l'offrir.

Il a, tout vacillant, la station d'un hautain

Mais grand Sphinx somnolant au fond du Sahara

Qui paraît s'assoupir dans un Oubli sans fin:

Son dos frôlant produit un influx angora

Ainsi qu'un diamant pur, l'or surgit, scintillant

Dans son voir nictitant divin, puis triomphant.

\section{Canção da Cisão (Vinicius)}

(O Sumiço)

Num piscar, do sorriso surgiu o pranto

Mudo ou obscuro ou Branco como a bruma

Ou das bocas unidas boca alguma

Ou do mimar das mãos mãos abanando

Num piscar, da bonança o furacão

Surgiu a sumir do olhar a última chama

Ou da paixão surgiu a má intuição

Ou do pausar das horas surgiu o drama

Num piscar, tão só num piscar dos olhos Surgiu no afortunado o malfadado

Ou no amor puro o mais duro dos ódios

Surgiu do amigo próximo o apartado

Ou da vida traçada um traço olvidado

Num piscar, tão só num piscar dos olhos 
Voyelles (Arthur Rimbaud)

A noir, E blanc, I rouge, U vert, 0 bleu: voyelles, Je dirai quelque jour vos naissances latentes.

A, noir corset velu des mouches éclatantes

Qui bombinent autour des puanteurs cruelles,

Golfes d'ombre ; E, candeurs des vapeurs et des tentes,

Golfes d'ombre ; E, candeurs des vapeurs et des tentes, Caps obscurs; qui, cristal du brouillard ou du Khan,
Lances des glaciers fiers,rois blancs,frissons d'ombelles; Harpons du fjord hautain,Rois Blancs,frissons d'anis I, pourpres, sang craché, rire des lèvres belles Dans la colère ou les ivresses pénitentes ;

U, cycles, vibrements divins des mers virides, Paix des pâtis semés d'animaux, paix des rides Que l'alchimie imprime aux grands fronts studieux;

Ô, suprême Clairon plein de strideurs étranges, Silences traversés des Mondes et des Anges: - Ô l'Oméga, rayon violet de Ses Yeux !
Vocalisations (Arthur Rimbaud) (La Disparition,125)|Vocalismos (Arthur Rimbaud) (O Sumiço)

A noir (Un blanc), I roux, U safran, $\mathrm{O}$ azur:

Nous saurons au jour dit ta vocalisation:

A, noir carcan poilu d'un scintillant morpion

Qui bombinait autour d'un nidoral impur,

I, carmins, sang vomi, riant ainsi qu'un lis

Dans un courroux ou dans un alcool mortifiant;

U, scintillations, ronds divins du flot marin,

Paix du pâtis tissu d'animaux, paix du fin

Sillon qu'un fol savoir aux grands fronts imprima;

O, finitif clairon aux accords d'aiguisoir,

Soupirs ahurissant Nadir ou Nirvâna:

O l'omicron, rayon violin dans son Voir !
A atro (Um branco), I rubro, U oliva, O azul:

Virá o dia no qual vamos vocalizá-lo:

A, atro, atroz, piloso fardo do moscardo

Borrachudo a assombrar um borro impuro, flou,

Cabo obscuro; qual cândida bruma, alvo Khan, Monarca Branco, altivo arpão, frio frisson?

I, púrpuras, o tísico cuspo, o batom

Rindo irado ou contrito no alcoólico afã;

Paz do animal no pasto, paz dos finos sulcos

Traçados por um logos nos cultos sobrolhos;

$\mathrm{O}$, augusto clarim bizarraço a tinir,

Suspiros cativando Nirvana ou Nadir:

ó o ómicron, violácio raio aos vossos Olhos!
U, ciclo, ondas divinas dos marinos fluxos, 